Ciência e Natura, Santa Maria v.38 n.2, 2016, Mai.- Ago. p. 780 -802

Revista do Centro de Ciências Naturais e Exatas - UFSM

ISSN impressa: 0100-8307 ISSN on-line: 2179-460X

\title{
CIÊNCIA'NATURA
}

\section{Renewable energy sources and analyzing the wind turbine performance; A Review}

\section{Erfan Shamsaddini lori and Zulkiflle Leman}

Department of Mechanical and Manufacturing Engineering, Faculty of Engineering, Universiti Putra Malaysia, Malaysia

\begin{abstract}
The potential of renewable energy resources has been investigated and its is shown that they can in fact fulfill most of the world's energy demand. In this study renewable energy sources such as biomass, solar, wind, geothermal and hydropower are studied and provided with sustainable energy services, based on the available natural resources. In the past three decades wind and solar power system have developed rapidly in sales, while there was a decline in their capital cost and costs of electricity generated. This study shows that the transition to renewable-based energy systems are increasing and continues to improve their performance characteristic. The enhancement and utilization of renewable energy sources can increase diversity in energy supply market, help to secure long term supportable energy supplies, keeping the environment clean by reducing local and global atmospheric emissions, establish marvelous options too encounter specific energy service needs by helping to create new job opportunities especially in developing countries.
\end{abstract}

Keywords: Renewable energy sources. Wind turbine, Solar. Ocean power 


\section{Introduction}

\subsection{Renewable Energy Sources}

Even though it has been proved that conventional energy sources such as oil, coal and natural gas are highly effective on economic progress, but at the same time causing harm to the environment and human health. The most critical challenge that might face in future by using of the coal is perhaps the greenhouse gas (GHG) reduction targets (referring to Kyoto protocol). It is now obvious that any attempt to sustain the atmospheric levels of $\mathrm{CO}_{2}$ even below 550 ppm is impossible based on an oil and coalpowered global economy.

Renewable energy sources are somewhere between $15 \%$ to $20 \%$ of world's total energy supply demand. A major part of this supply is dominated by traditional biomass which is mostly fuel wood and another large contribution is obtained by hydropower where nearly $20 \%$ of the global electricity supply is covered by this source. A small portion of this supply is currently contributed by new renewable energy sources such as solar energy, modern bio-energy, wind energy, geothermal energy and small hydropower. In this chapter there will be a brief review on each and every one of these sources and at last there will be an introduction to wind power systems and wind turbines in more details which meets the purpose of this research.[1]

\subsection{Biomass Energy}

Biomass is entitles to all substantial material coming from plants, tress, corps and collection and storage of the sun's energy through photosynthesis. Biomass energy is the convention of biomass into beneficial forms of energy such as electricity, heat and liquid fuels. Biomass for bio-energy either comes directly from the lands or from the remainders obtained in the processing of food or corps or products such as paper from the wood industry. Another essential portion comes from the consumer remainder such as demolition wood, pallets being used in transportation and also a fraction of urban solid waste. The biomass can be used indirectly as well in the form of intermediate energy carrier called bio fuels, these includes higher energy density solid fuels, liquid fuel and gasification of biomass. The various sources and application are shown in Figure 1.1.

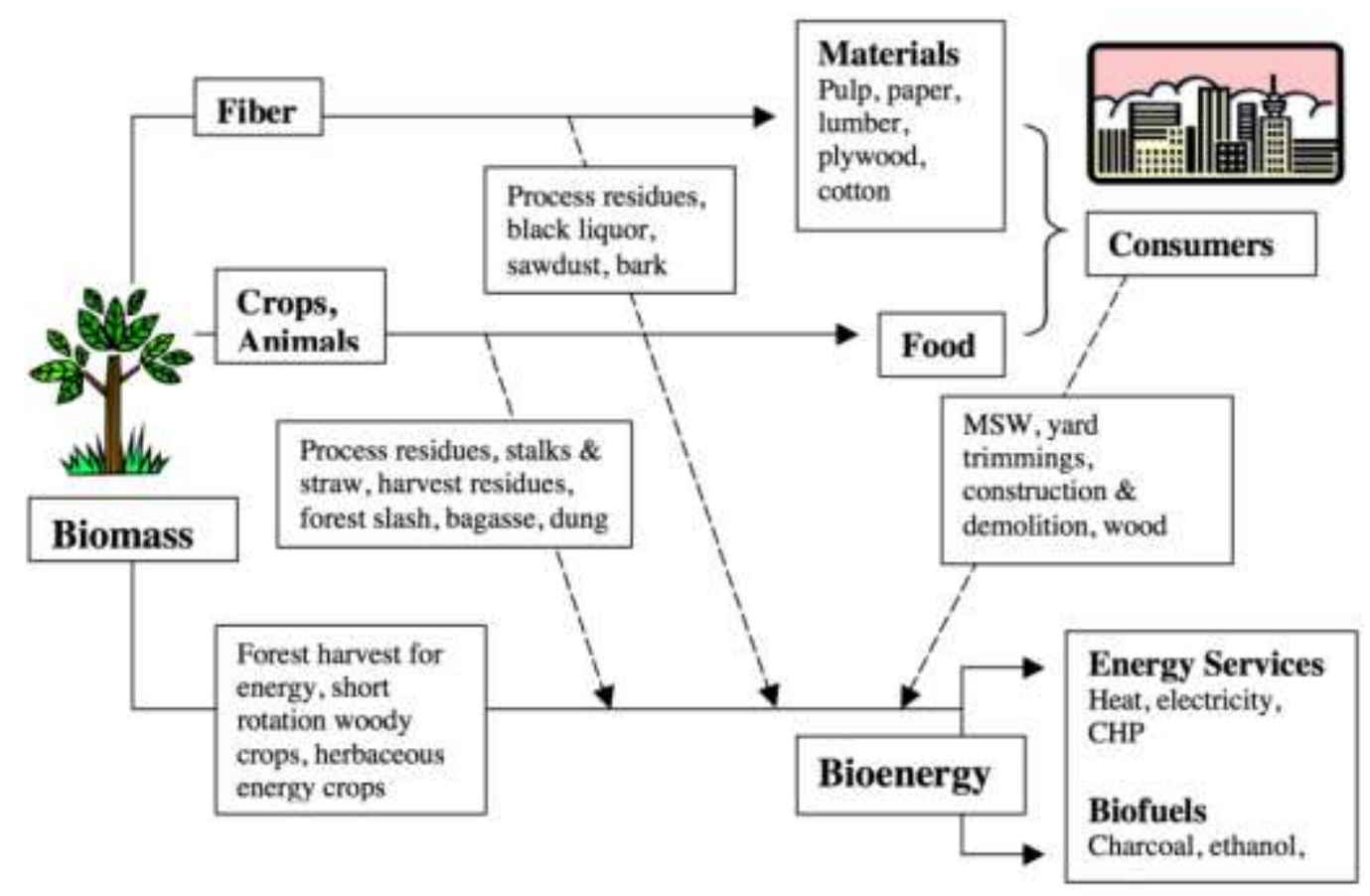

Figure 1.1 Schematic flow chart of Biomass and Bio-energy 
Such a huge contribution of this source of energy supply might raise concerns about local and regional environmental and socio-economic impacts. Such issues include:

a) Discharge of soil nutrients from crop land due to the removal of agricultural remainder

b) Leaching of chemicals utilized to intensively-cultivated biomass energy crops

c) Reducing in biodiversity due to the land conversion to energy crops

d) Using of biomass resources for nonenergy purposes, or using of land form food to produce energy

That is why compare to the other types of energy system bio-energy systems are more inextricably linked to their local environmental and socio-economic backgrounds.

\subsubsection{Biomass Energy Conversion} Technologies and Applications

There are varieties of methods being used to generate modern energies such as electricity, gas and liquid fuels from biomass these technologies are classified in terms of either the conversion process they use or the end product produced as follow:
a) Combustion
b) Gasification
c) Anaerobic Digestion
d) Liquid Bio fuels

\section{A) Combustion:}

Direct combustion is still the most common technique used for extracting energy from biomass for both electricity and heat purposes. The fired heating systems are very popular in colder climates, even recent improvements led to a automated heating systems where standardized fuel are being used together with catalytic cleaning gas.

The main technology being used from biomass for electricity generation is the steamRankine cycle (see figure 1.2).The process starts with direct combustion of biomass in a boiler which results in raising the steam that later will be expanded through a turbine. This technology has been used and introduced into industry more than 100 years ago. The energy conversion efficiencies are relatively low (almost between 15 to 25 percent) and it is due to their small sizes. One of the huge advantages of this technology which makes it high in terms of efficiencies level is that combined heat and power (CHP) is generated from the system. the waste heat generated from the heat steam can be recovered and used for other needs specially industrial processes, that is why steam cycle plants are often placed at industrial sites. Another advantages of this technology can be its economical aspect since it does rely on low, zero or negative cost biomass because of the highly available biomass material in many regions of the world such as sugarcane processing industries or sawmills and forest product industries.[1]

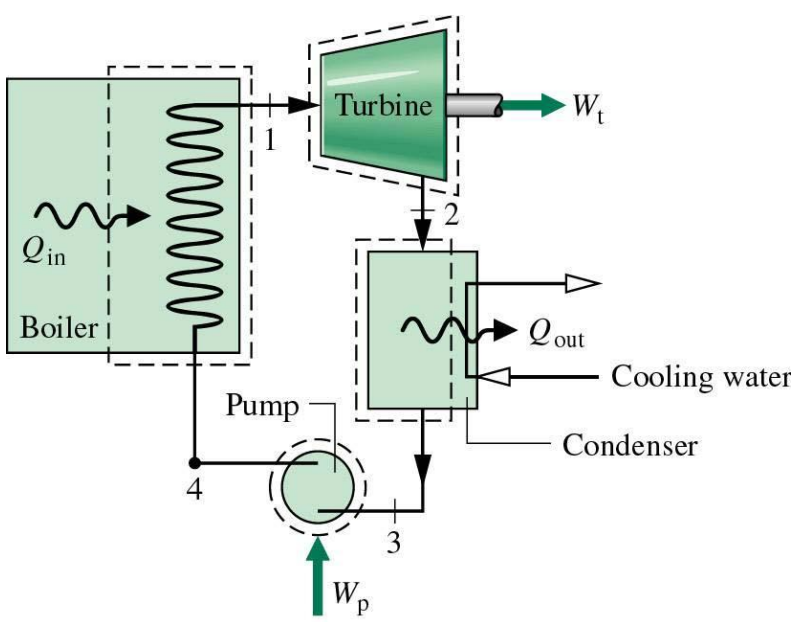

Figure 1.2 Schematic diagram of steam Rankine cycle process 
B) Gasification:

The term gasification is refereeing to the hightemperature thermo chemical conversion which through it combustible gas can be produced, this combustible gas is called producer-gas. Producer-gas contains carbon monoxide, carbon dioxide, hydrogen, nitrogen with a heating value of 4 to $6 \mathrm{MJ} / \mathrm{Nm}^{3}$ or 10 to 15 percent of the heating value of natural gas. The producer-gas is the result of burning biomass without sufficient air for full combustion, but with enough air to convert the solid biomass into a gaseous fuel.

One technology which is the wide interest of researchers is the biomass integrated gasification combined cycle (IGCC) being used for larger scale power and combined with heat and power
(CHP) generation on the range of 5 to $100 \mathrm{MWe}$. IGCC system starts with sizing and drying of raw materials and continues with thermo chemical gasification to produce the combustible gas, cooling and cleaning the gas, and combustion in a gas turbine. Hot exhaust of the gas turbine is used to raise the steam which operate the steam turbine for additional generation.

One of the main technical challenges for generating electricity by gasifier systems, at any scales, is satisfactorily removing the tars and oils from the producer-gas in order for the system to operate more efficiently, economically and to minimal toxic and air emissions.[1]

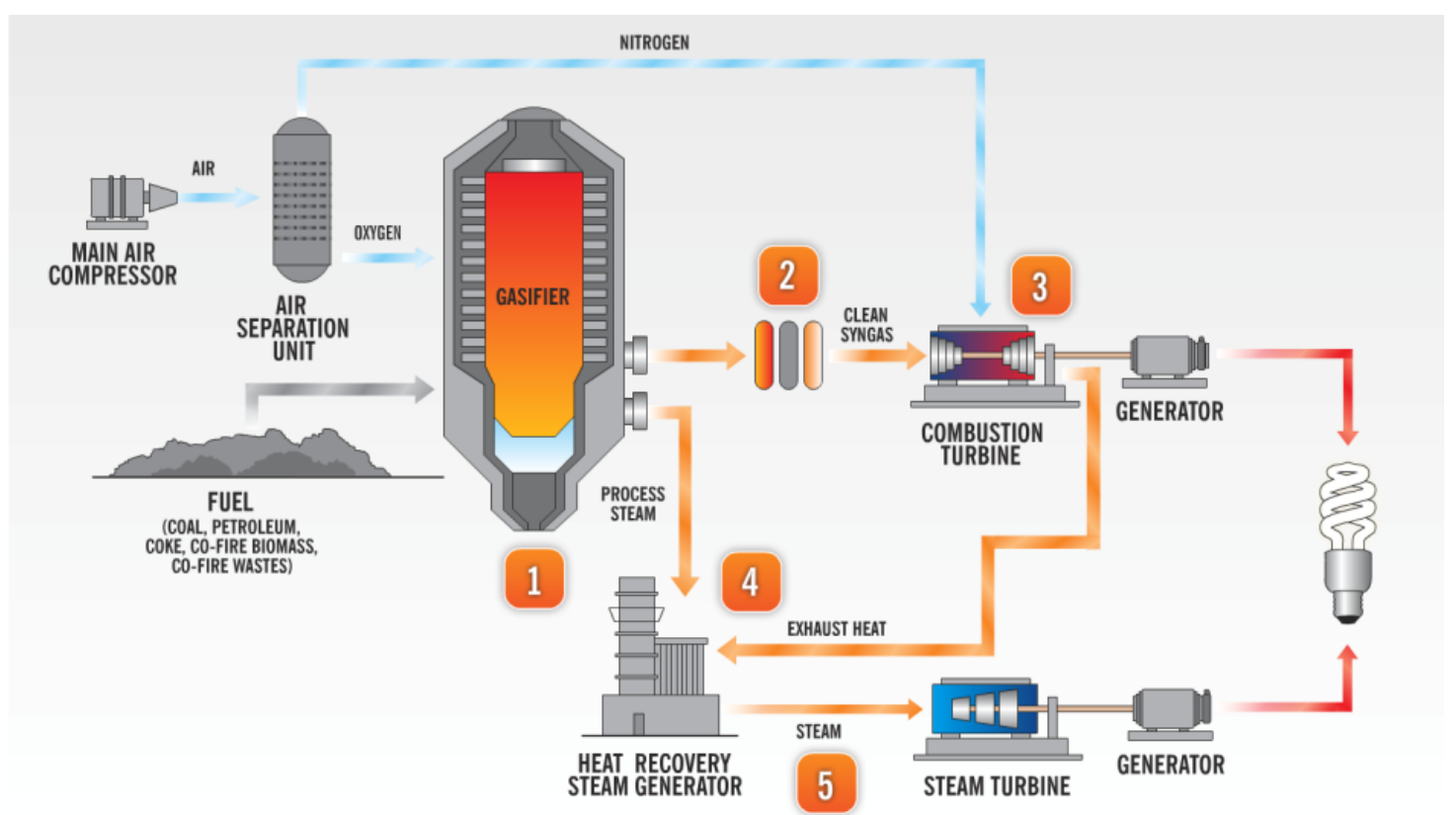

Figure 1.3 process involved in Gasification

Process 1 : Gasifier converts coal and oxygen into a synthesis gas (syngas), as well as produce steam.

Process 2 : The hot syngas is processed to remove sulfur compounds, mercury and particulate matter.

Process 3 : The clean syngas is used to fuel a combustion turbine generator, which produces electricity.

Process 4 : The heat in the exhaust gasses from the combustion turbine $s$ recovered to generate additional steam.
Process 5 : Recovered steam, along with that from the syngas process, drives a steam turbine generator to produce additional electricity.

C) Anaerobic Digestion:

Another way to obtain combustible gas from biomass is through the low temperature biological processes called anaerobic (without air) digestion. The common ways to produce this gas is either in particularly designed anaerobic digesters or from the landfills by capturing the naturally produced methane, the gas produced from this process is called biogas which contains 
of $60 \%$ methane and $40 \%$ carbon dioxide with a heating value of $55 \%$ of natural gas. Biogas can be obtained from almost any biomass such as animal and human wastes, sewage sludge. Crop remainders, heavy carbon industrial processing byproducts.

Anaerobic digesters generally comprise of three major parts; an inlet where all the organic materials, residues and wastes are fed into the digester tank; a tank where the heating process is performed and all the biomass materials are heated up to the decomposition rate and partly convert by bacteria into biogas; and an outlet where the biomass that accomplished the process and all the non-digested materials remains as sludge can be removed from the tank (see Figure 1.4). One of the advantages of this process is the non-energy benefits of this process which can be obtained directly from the sewage discharged from the digesters in a form of concentrated nitrogen fertilizer.

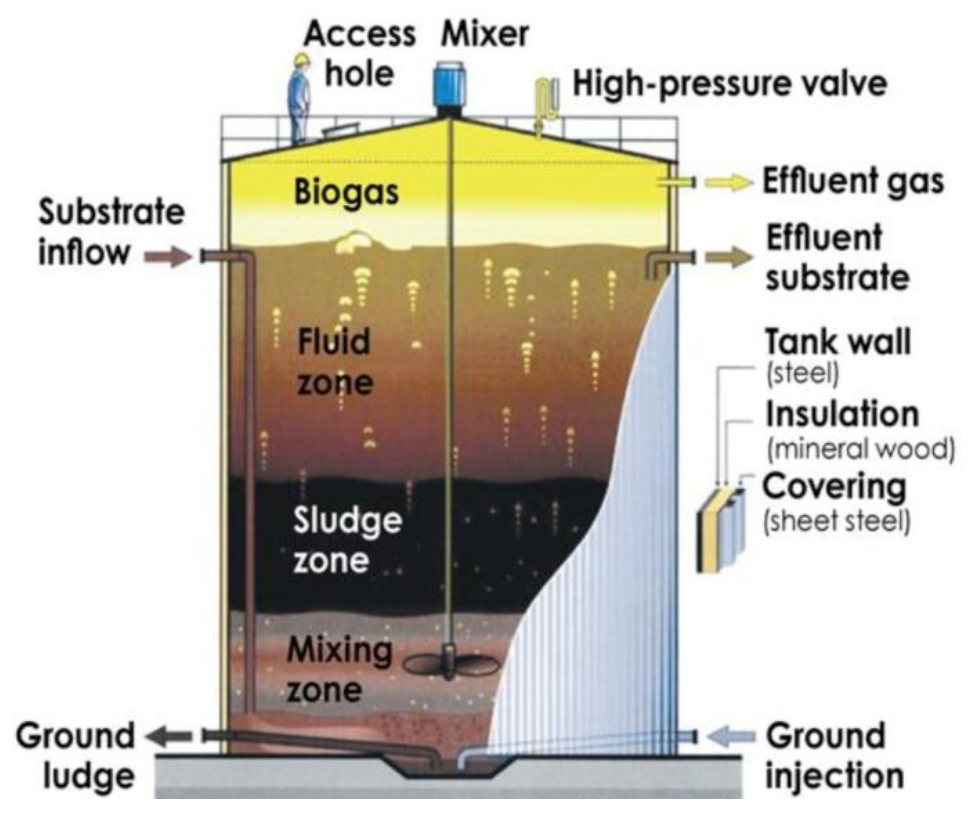

Figure 1.4 Schematic diagram for Anaerobic digester tank

\section{D) Liquid Bio-fuels}

Biomass can also be converted through processes into more useful intermediate form of energy called bio-fuels. One of the interest of converting solid biomass into liquids is due to their potential ability to replace petroleum-based fuels used in transportation sector. However, adopting this new liquid bio-fuels into present engine technology has been proven to be nontrivial. The only alternatives that can produce compounds similar to hydrocarbon petroleum products includes oil producing plants, such as soybeans, palm oil trees and oilseeds like rapeseeds. Another type of liquid fuels produced from gasified biomass is a class of synthesized hydrocarbons called Fischer-Tropsch (F-T) liquids. F-T fluids can be utilized as a sulfur-free diesel or blended with existing diesel to reduce emissions which has a good impact on the environment.. In addition, there are more efficient to be used as automotive fuels, cleaner cooking fuel to replace the old traditional wood fuels.

1.3 Solar Thermal Systems and Solar Photovoltaic

Aside from biomass-based systems convert sunlight into useful form of energy by using photosynthesis from plants as an intermediate step. There are two main technologies which convert sunlight into energy as well. First, solar photovoltaic (PV) modules which convert sunlight directly into electricity and second, solar thermal power systems which focus the solar radiation to generate steam which is then used for turning the turbine for producing electricity. 
The following gives a brief explanation and introduction about these technologies.[2]

\subsubsection{Solar Photovoltaic's}

Solar units are solid-state semiconductor devices with no moving part that directly convert sunlight into electricity current (see Figure 1.5). The basic law underlying the operation of this unit goes back more than 150 years ago, but the major application of PV technology was to power up satellites in the late 1950s. since that time a lot of researches and developments was done to increase the performance and reduce the cost there are many advantages regarding the technical and economic aspect of use of PV technologies, but common among them will be durability, lack of moving parts in the system, high efficiency, quiet operation, and the fact that these features combine to provide power source low maintenance and incomparable durability.

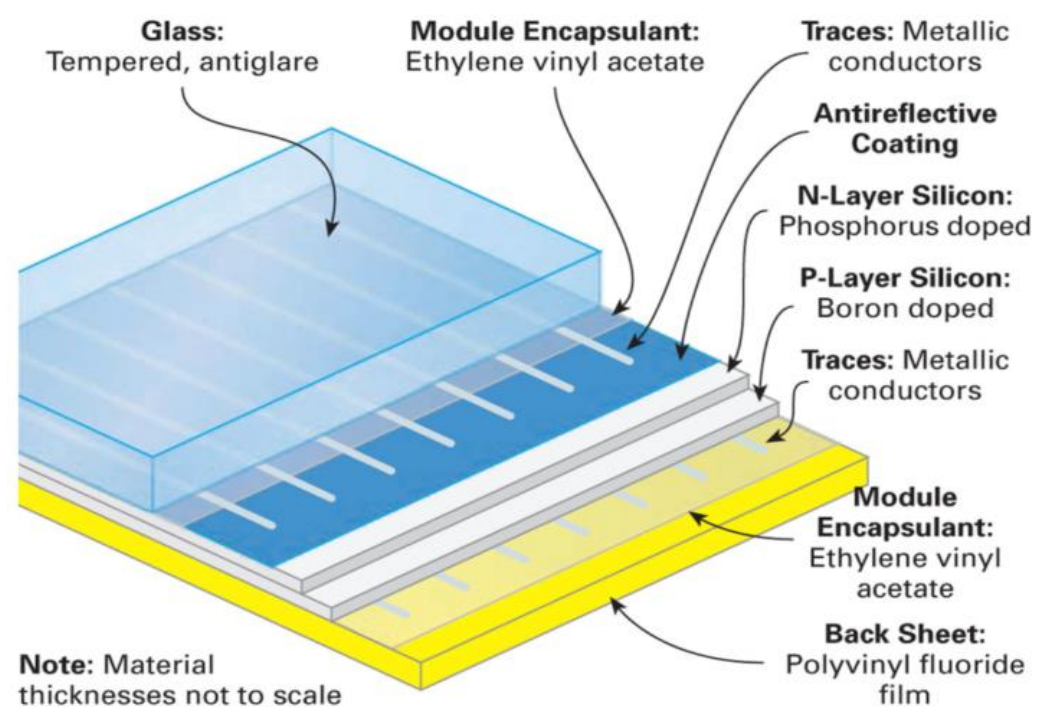

Figure 1.5 The Anatomy inside the PV cell

\subsubsection{Solar Thermal System}

As was mentioned earlier above, there are various techniques available to focus sunlight in order to heat an intermediary fluid, recognized as heat transfer fluid which then is used to generate. Because the system includes a thermal intermediary it can be upgraded with hybridized with fossil fuel and even in some cases can be utilitized with a thermal storage. The advantages of these technologies are that it can provide dispatchable power whereby the system can operate during periods when there is a lack of solar energy, it can also enhance the economic value of electricity produced and reduce average cost. The steam is then used to run the steam turbine for generating electricity. Mainly there are three thermal power systems available today which introduced as follow:

a) Parabolic troughs solar thermal systems: these systems use parabolic trough-shaped mirrors in such a way to focus sunlight on thermally efficient receiver tubes that having heat transfer fluid inside them. This fluid is heated up to $390^{\circ} \mathrm{C}$ and pumped into sequences of heat exchangers to produce superheated steam which then cause the turbine generator to produce electricity.(see Figure 1.6) 


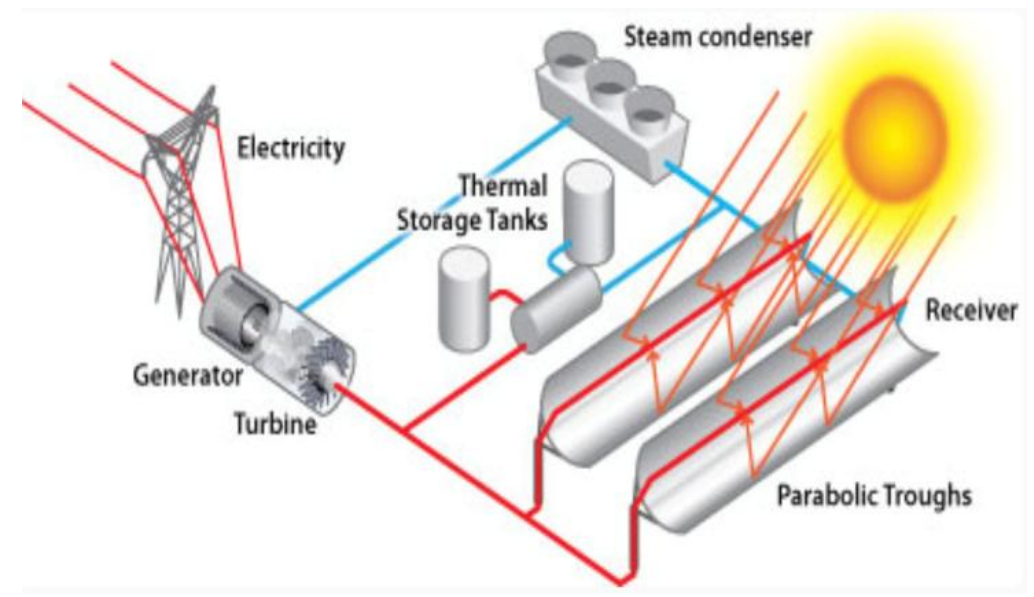

Figure 1.6 Schematic diagram of a typical Parabolic troughs solar system

b) Power towers solar thermal systems: They use circular array of large individually-tracking mirrors to focus sunlight on to a receiver which is mounted on top of a tower (see Figure 1.7). in 1992 a new system was introduced and added to the current system by a consortium of U.S. utilities. In the new system a molten-salt receiver along with a thermal storage system was installed. The addition of this system made the power tower unique since it provides dispatchable power and increased the load factors up to $65 \%$.

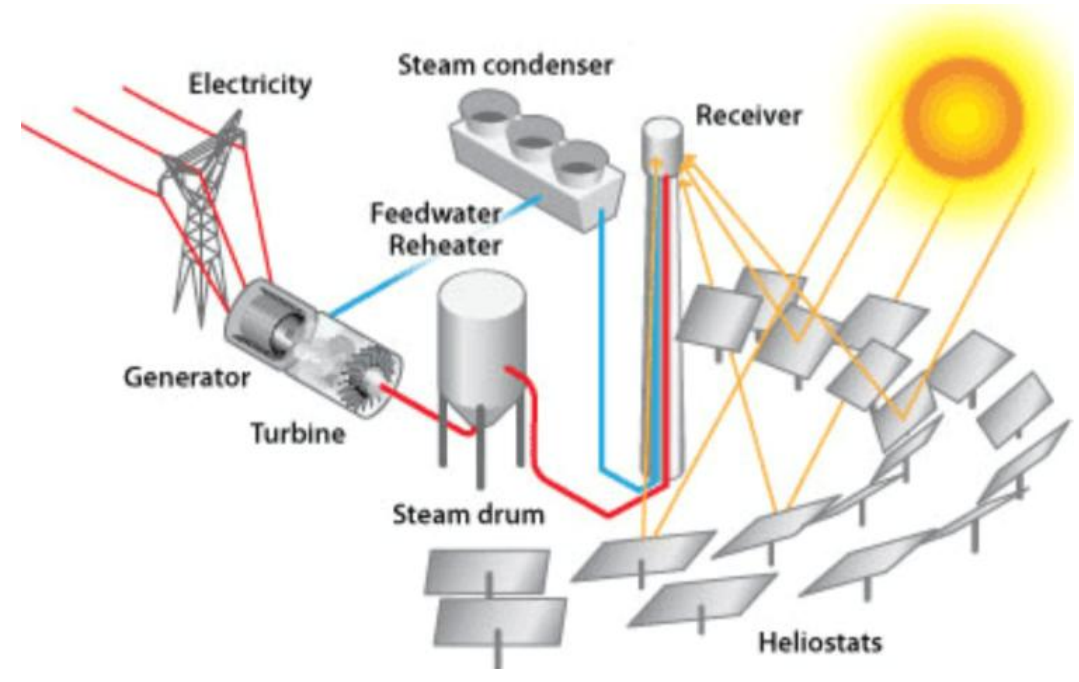

Figure 1.7 Schematic drawing of a power tower system

c) Dish/engine systems solar thermal systems: this model is still in the prototype scale, use an array of parabolic dish- shaped mirrors to focus solar energy onto a receiver located at the focal point of the dish. This causes the fluid in the receiver to be heated up to $750^{\circ} \mathrm{C}$ and used to produce electricity in a small engine attached to the receiver. The engines are still under consideration (Stirling and Brayton-cycle engines).(see Figure 1.8) 


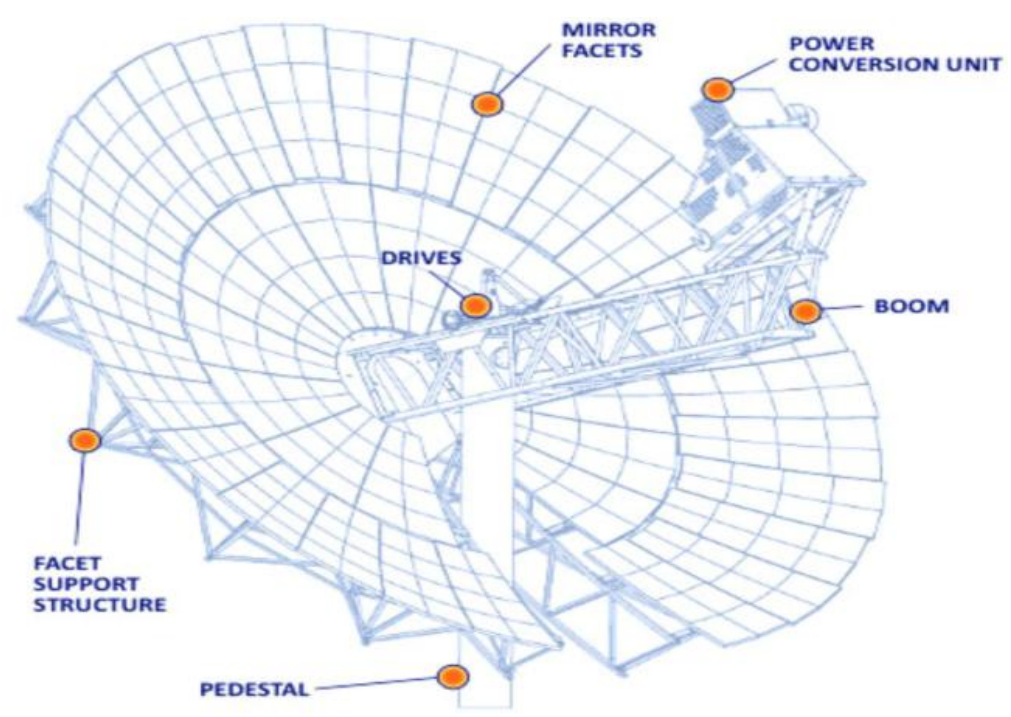

Figure 1.8 Improved solar power dish with Stirling engine

\subsection{Hydropower}

Hydropower is the largest renewable resources used for electricity. More than 150 countries are generating hydroelectric power. The power is derived from falling water which is then cause the turbine's blade to rotate and result in producing electricity.(see Figure 1.9)

Although hydroelectricity is known as a clean energy source, it is not entirely free of greenhouse gas emissions (GHG) and it can be often harmful and have socio-economic impacts. Environmental impacts are also significantly high since it includes reduction in fish population, spreading of water-related diseases and also sedimentation that can destroy river habitat. Another disadvantages that have an social and economically impact on the project involves mitigating of people from the area which the dam is planned to be built.[2]

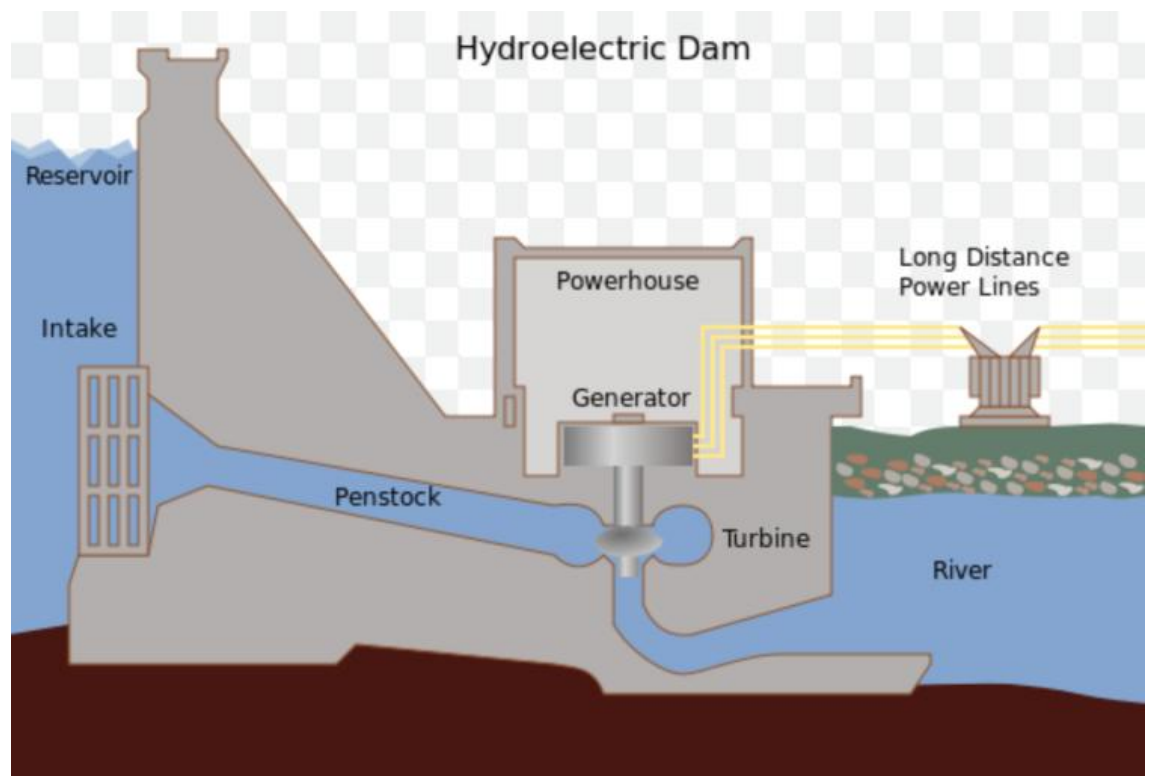

Figure 1.9 Schematic diagram of hydropower system 


\subsection{Geothermal Energy}

There is an enormous amount of heat which arises from the heat remaining in the Earth's core and it is produced naturally from the friction between sliding plates beneath each other and from the decomposition of radioactive elements that occur in small amounts in all rocks. People have profited from this resource of energy through hot springs and steam vents for thousands of years for cooking, heating and bathing purposes but with development in technology it became possible to extract hot water or steam from layers close to the surface by drilling into hydrothermal reservoirs and either using it to generate electricity or directly use it for space heating or industrial processes.(see Figure 1.10)

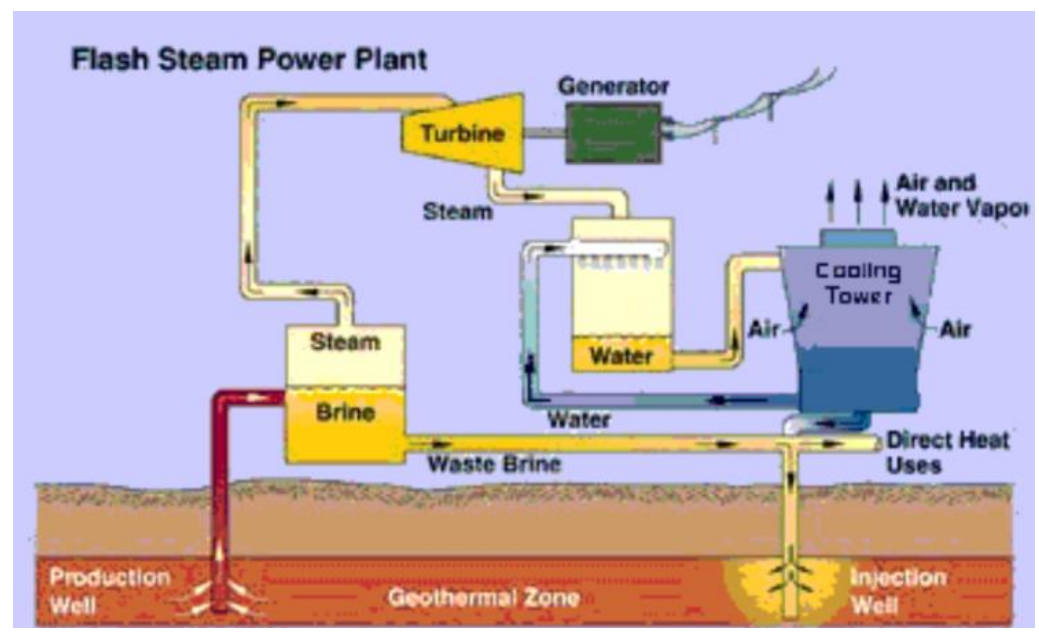

Figure 1.10 Schematic diagram of flash steam power plant

The amount of geothermal energy is massive. It has been estimated that only $1 \%$ of heat stored in the uppermost 10 kilometers of the earth's crust is equivalent to 500 times the energy that can be obtained from all oil and gas resources. Despite the fact that this source of energy is interminable, yet it is unevenly distributed which makes the extracting process difficult both industrially and economically.

\subsection{Wind energy}

Wind has considerable potential as a global clean energy source, being both widely available, though diffuse, and producing no pollution during power generation. Wind energy has been one of humanity's primary energy sources for transporting goods, milling grain, and pumping water for several millennia. From windmills used in China, India and Persia over 2000 years ago to the generation of electricity in the early 20 century in Europe and North America wind energy has played an important part in our recorded history. As industrialization took place in Europe and then in America, wind power generation declined, first gradually as the use of petroleum and coal, both cheaper and more reliable energy sources, became widespread, and then more sharply as power transmission lines were extended into most rural areas of industrialized countries. If the mechanical energy is used directly by machinery, such as a pump or grinding stones, the machine is usually called a windmill and If the mechanical energy is then converted to electricity, the machine is called a wind generator [3].

\subsubsection{Types of wind turbines}

Today there are various types of wind turbines in operation, (Figure 1.11). The most common device is the horizontal axis wind turbine. This turbine consists of only a few aerodynamically optimized rotor blades, which for the purpose of regulation usually can be tumbled about their long axis (Pitch-regulation). Another cheaper way to regulate it, consists in designing the blades in such a way that the air streaming along the blades will go into turbulence at a certain speed (Stall-Regulation). 
These turbines can deliver power ranging from $10 \mathrm{~kW}$ to some MW. The largest turbine on the European market has a power of 3.6 MW, bigger machines are testing. The efficiency of this type of turbine is very high. Therefore, it is solely used for electricity generation which needs "high speed engines" to keep the gear transmission and the generator small and cheap.
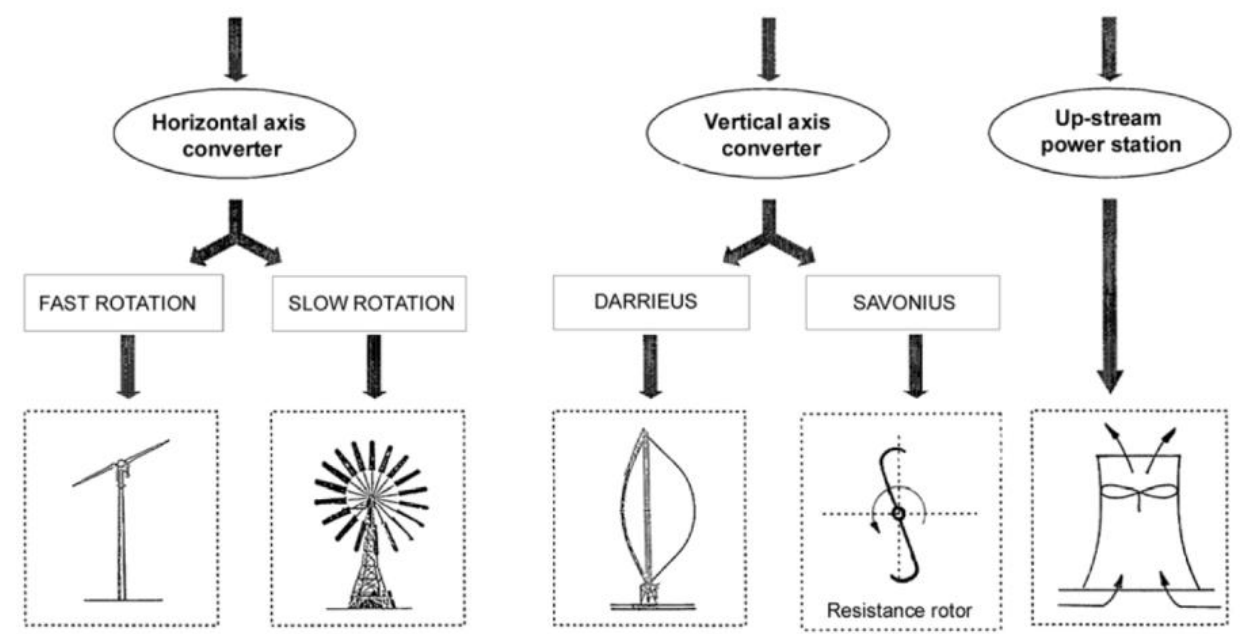

Figure 1.11 The illustration of different types of wind turbines

\subsubsection{Componenets of wind tubine}

The wind turbines is comprises of three main components; Rotor blade, Nacelle and Tower (Figure 1.12).The nacelle contains the key components of the wind turbine, including the gearbox, and the electrical generator.

The tower of the wind turbine carries the nacelle and the rotor. Generally, it is an advantage to have a high tower, since wind speeds increase farther away from the ground. The rotor blades capture wind energy and transfer its power to the rotor hub. The generator converts the mechanical energy of the rotating shaft to electrical energy .The gearbox increases the rotational speed of the shaft for the generator

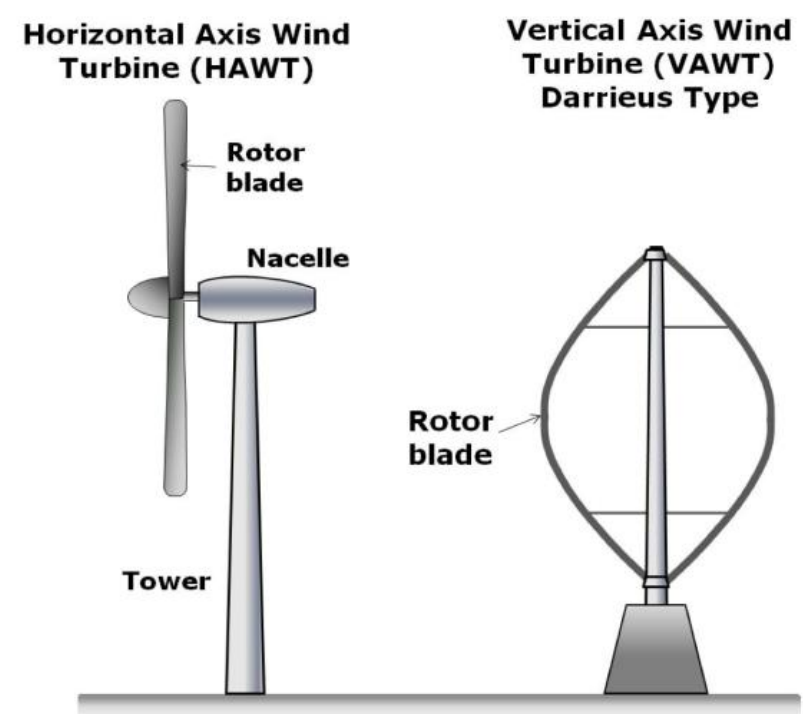

Figure 1.12 Main components of the horizontal and vertical axis wind turbines 


\subsubsection{Energy content of the wind turbine}

The following section will be used to mathematically explain where the energy in the wind comes from and what factors it depends on.

Power is defined as:

$$
P_{o}=\frac{1}{2} \rho \cdot A \cdot V^{3} \cdot C_{P}
$$

where

$$
C_{P}=\frac{\left(1+\frac{V_{o}}{V}\right)\left[1-\left(\frac{V_{o}}{V}\right)^{2}\right]}{2}
$$

The $C_{P}$ is the fraction of the upstream wind power, which is captured by the rotor blades[4]. It has the maximum value of 0.59 when the $\left(V_{0} / V\right)$ is one-third. The maximum power is extracted from the wind at that speed ratio, when the downstream wind speed equals onethird of the upstream speed. Under this condition:

$$
P_{\max }=\frac{1}{2} \rho \cdot A \cdot V^{3} \cdot 0.59
$$

Figure 1.13 shows the typical wind turbine power output with steady wind speed, it can be seen that the power output per $\mathrm{m}^{2}$ of the rotor blade is not linearly proportional to the wind velocity, as proven in the theory above. This means that it is more profitable to place a wind turbine in a location with occasional high winds, than in a location where there is a constant low wind speed. Measurement at different places shows that the distribution of wind velocity over the year could approximate by a Weibullequitation. That means that at least about $2 / 3$ of the produced electricity will be earned by the upper third of wind velocity.[2]

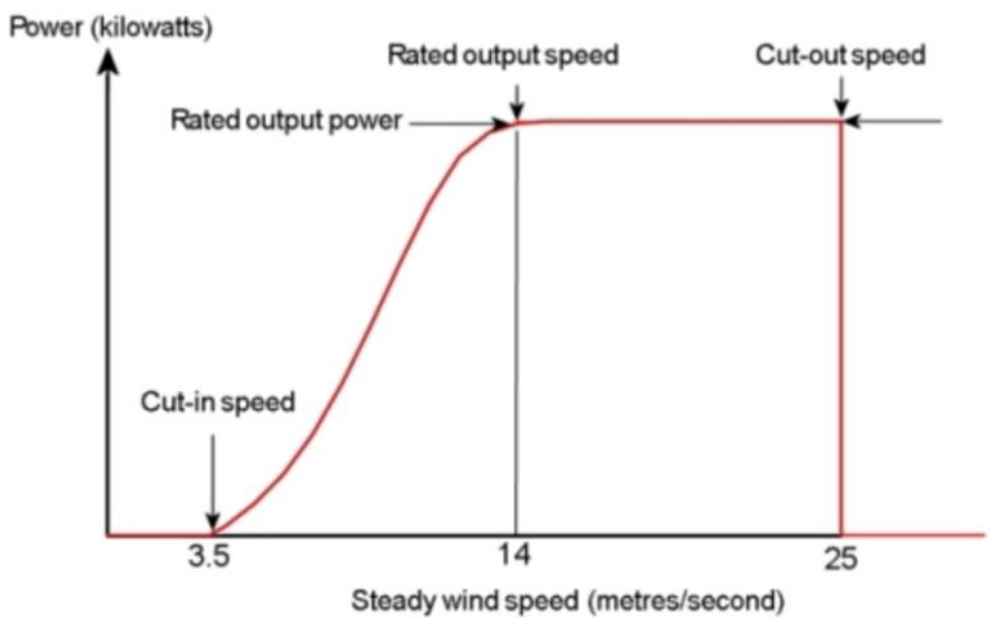

Figure 1.13 Diagram for a typical wind turbine power output with steady wind speed

\section{Cut-in speed.}

At very low wind speeds, there is insufficient torque exerted by the wind on the turbine blades to make them rotate. However, as the speed increases, the wind turbine will begin to rotate and generate electrical power. The speed at which the turbine first starts to rotate and generate power is called the cut-in speed and is typically between 3 and 4 meters per second.

\section{Rated output power and rate output wind} speed.

As the wind speed rises above the cut-in speed, the level of electrical output power rises rapidly as shown. However, typically somewhere between 12 and 17 meters per second, the power output reaches the limit that the electrical generator is capable of. This limit to the generator output is called the rated power output and the wind speed at which it is reached is called the rated output wind speed. At higher wind speeds, the design of the turbine is arranged to limit the power to this maximum level and there is no further rise in the output power. How this is done varies from design to design but typically with large turbines, it is done by adjusting the blade angles so as to keep the power at the constant level.

\section{Cut-out speed.}


As the speed increases above the rate output wind speed, the forces on the turbine structure continue to rise and, at some point, there is a risk of damage to the rotor. As a result, a braking system is employed to bring the rotor to a standstill. This is called the cut-out speed and is usually around 25 meters per second [5].

Being able to measure the swept area of your blades is essential if you want to analyze the efficiency of your wind turbine (Figure 1.13).
The swept area refers to the area of the circle created by the blades as they sweep through the air.

To find the swept area, use the same equation you would use to find the area of a circle can be found by following equation:

$$
A=\pi r^{2}
$$

where $\mathrm{r}$ is the radius of the circle. This is equal to the length of one of your blades.

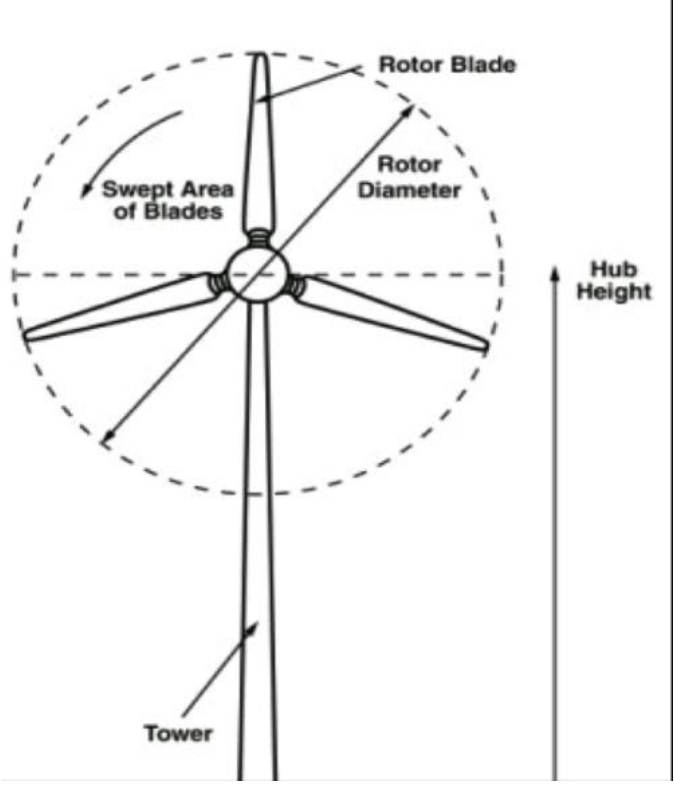

Figure 1.13 Illustration of the Swept area of the rotor blades [5]

1.6.4 Factors affecting the efficiency of the wind turbine

\section{Length of blades}

Length of turbine blade plays a crucial role in determining how much wind power can be captured, according to the swept area of rotor disc. According to Betz's limit it's never possible to harness more than 59 percent of total energy of the wind.

\section{Aerodynamic section of blades}

The rotation of the turbine blade depends up on the aerodynamic section. There should be an aerodynamic profile in order to lift and rotate turbine blades.

\section{Platform shape}

To maintain a constant slowing effect across the swept area, the

platform shape should be narrower towards the tip. This design is to ensure that neither the air is too slow or too fast. Faster wind

speed would lead to energy loss and slower wind would lead to

turbulence.

\section{Aerofoil thickness}

Each blade is a aerofoil. The thickness of aerofoil increases towards the root to withstand structural loads. 


\section{Blade twist}

The blade must be twisted along its length to maintain optimum angle of attack of the blade section to the wind.

\section{Blade number}

There are usually no more than three blades. If there is more than three each blade must be narrower, hence thinner. It is very difficult to maintain the strength of thin blades. That's why we

prefer to use not more than three blades.

\section{Rotational speed}

Usually rotational speed of blade (rotational speed is measured from the blade tip) is between seven to ten times the wind speed. Higher wind speed means each blade must be narrower (which is difficult).

\section{Pitch control}

Wind speed varies greatly according to the climate, season, etc. Pitch control mechanism is provided within the turbine itself to

'withstand higher wind speeds' and produce power in low wind speeds'. The blades may be pitched either into the wind or away from the wind to regulated the generated power.

1.7.5 Disadvantages and limitations of wind turbine

\section{1) It is Dependent on the Availability of Wind}

Disadvantages of wind energy include the fact that it relies entirely on the availability of wind. As long as there is no wind no electricity will be produced. As such, this form of energy cannot be relied on in totality as it is bound to fail every now and then. Due to the fact that this form of energy is not reliable, electricity generators do not invest on it and as such, its technology is not improving. There is therefore a high likelihood that this form of energy will be done away with eventually as the technology of other forms of energy is improving with leaps and bounds.[6]

\section{2) Wind Turbines Kill Birds}

Wind turbines are usually made of blades that rotate continuously and fiercely. Due to the fact that the blades are usually placed high up in the air, they are known to kill birds that fly over it. A research was done that showed that about 45,000 birds that flew over wind turbines have been killed over the past 20 years. The birds that are affected the most are the ones that usually migrate annually, these birds include; kestrels, golden eagles and tailed hawks. Attempts have been made to prevent more birds from dying as they paint the blades with conspicuous colors so that the birds can see and avoid them.

3) The Speed of the Blowing Wind Has to Be Right

So as to produce the right amounts of electric power, the wind turbines need to rotate at the right pace. The rotation should neither be too slow nor too fast. When the speed of the wind is extremely slow, it is not economical for the turbines to run. This is because the turbines are quite expensive to run. When there is too much wind that is blowing at a fast rate, it is mandatory that the turbines are shut down owing to concerns of safety as if the wind is so strong the turbines might get destroyed or might get detached and hurt people.

\section{4) The Energy Density of Wind Is Low}

Due to the fact that wind is diffuse and it is also spread over a wide area, so as to be able to produce large quantities of electricity it is mandatory that the number of turbines used cover a large area. Since many turbines have to be used, the costs of setting up a wind farm are so high. However, the production of other sources of energy faces the same problems.

\section{5) This Form of Energy is Not Efficient}

The system that is usually set up so as to turn wind energy into electric energy is not efficient. This happens to be one of the major disadvantages of this form of energy. The turbines do not have the ability to extract a hundred percent of the energy that is found in the blowing wind 
6) The Energy that is Produced Can't Be Stored in Large Scale

The energy that is produced cannot be stored in large scale. Considering the fact that it is impossible to have wind blowing daily, it is important that the energy storage of this system be sufficient. Seeing as it is not, this shortcoming contributes greatly to the insufficiency of wind energy. Needless to say, this problem is likely to be there for a very long time.

\section{7) The Turbines are Noisy}

One of the reason as to why most people avoid using this form is energy is that the machinery that is used for the production of electricity is very noisy. Although this form of energy is preferred as it does not pollute the environment, the noise that is usually produced in the process of producing electricity is too much: it can be a nuisance. As such, the system setups for this form of power cannot be placed in places that need to be quiet such as residential areas and places of works. This limits the number of places where the setups can be put up.

8) The Amount of Wind that Blows Is Unpredictable

The amount of wind that is likely to blow in a particular place at a particular time is impossible to predict. This is one of the major disadvantages of wind energy as one has to invest on other alternatives forms of energy. As such one has to incur double costs so as to ensure that they have enough electricity. The best alternatives of energy are geothermal and solar energy. As a result of this shortcoming, before setting up a wind farm, thorough research has to be done so as to make sure that the location is appropriate.

9) This Form of Energy is Suited to Be Set Up in Specific Places

Wind farms can only be set up on specific places. This limits the use of this form of energy to specific places. The best place to set up a wind farm is in the coastal regions. The reason as to why turbines are placed in the coastal region is due to the fact that coastal regions are always windy. This means that regions which are located hilly areas may not be able to benefit from this form of energy. The place where the turbines are placed ought to have a lot of wind blowing if any electricity is to be produced.

10) The Visual Impact that Turbines Have on the People

Many people are of the ideas that turbines are not appealing to the eye. There is however people who tend to think that they beautify the areas as they are appealing to the eyes. The different views have resulted into people filing petitions to bar the setting up of wind farms in areas that surround them. The fact that there are people who find turbines undesirable is a shortcoming of this form of energy as its use is limited to places where they are accepted.

\section{1) Land Use}

One of the main disadvantages of wind energy is that large tracks of land are needed to so that the appropriate number of turbines can be installed. One of the major reason as to why the installation of turbines is considered to be a waste of time is because the electrical energy that is usually produced is too little to warrant the wastage of huge tracks of land. The fact that a safe area has to be around each farm contributes to wastage of land..

\section{2) Poor Electricity Production}

Many people wonder whether the little electricity produced is worth the costs that come with the buying of the turbines and towers. The amount of electricity that is produced is very little and not worth the cost of installing the wind farms.

13) Turbines Interfere With the Reception of Televisions

Many of the people who live near wind farms complain that the wind turbines interfere with their television signals. This explains why most people protest against the putting of wind farms in residential places. Turbines are also known to interfere with radio signals.

The disadvantages of wind energy cannot be ignored. Some of these limitations are so great that they cannot be ignored. Limitations such as the fact that the amount of electricity that is produced is not worth the costs that were 
incurred to make the wind farms is a major limitation that has to be considered before setting up a wind farm. Wind energy is not a reliable source of power as there are days when the wind will not blow and this result into a situation where electricity will not be available until the wind begins to blow again. It is important to have a reliable source of power as lack power interferes with almost all activities that take place in daily living. The fact that this form of energy is not likely to improve makes it more undesirable.

\subsection{Ocean power}

Day and night, around the world, the force of the sea can be seen and heard, crashing onto beaches and rocky shores. The endless cycle of waves, tides and currents is driven by wind, the gravitational effects of the moon and ultimately, the power of the sun.

Following decades of research, the ability to tap into this formidable source of energy is finally within our grasp. What it promises is seduc- tive: a limitless and dependable supply of clean energy, accessible on shore and yet largely out of sight, helping to reduce our dependence on fossil fuels and thus our footprint on planet Earth.

Tapping into the power of waves and tides to generate electricity also prom- ises to create a vibrant new energy sector, offering jobs (up to 420000 by 2050) and economic growth, especially for areas suffering from the decline of traditional maritime industries such as shipbuilding and fisheries.[7]

Estimates suggest wave and tide energy could satisfy $15 \%$ of European electricity demand; by 2050, it could help Europe avoid 136 $\mathrm{MT} / \mathrm{MWh}$ of $\mathrm{CO}_{2}$ emissions.

Most marine energy technologies are still at the demonstration phase, but several projects are showing excellent results, including the following:

@囚The European Marine Energy Centre (EMEC) in Orkney, Scotland, which provides testing facili- ties for technologies such as the
Oyster wave converter developed by Aquamarine Power.

๑®In Spain's Basque Country, the Mutriku wave power plant consists of 16 turbines of $18.5 \mathrm{~kW}$ each, with an estimated overall power of $296 \mathrm{~kW}$.

๑®Wave Star in Denmark has received funding to upscale and demonstrate a $500 \mathrm{~kW}$ wave pow- er unit in the North Sea.

(อ®) French power company EDF and Irish firm Open- Hydro are developing the world's largest tidal energy plant at Paimpol-Bréhat in Brittany.

The two most promising technologies for early commercial development in Europe and wave and tidal power:

1. Wave power: Devices can be bottommounted or floating and sited at various distances from the shore, but all derive their energy from the movements and power of waves.

2. Tidal energy: which itself is devided in to two methods; current and barrage. In current system devices areplaced in stream and generate energy from the flow of water. Ideal locations are around peninsulas and through restricted channels, such as between islands and the shore.In barrage systems, they use the rise and fall of tides in estuaries and bays to produce electricity. The technologie are well developed and work is continuing to develop strategies to minimise environmental impact.

Other technologies such as temperature; The difference in temperature between warm surface waters and cool deep waters can be harnessed by ocean thermal energy conversion (OTEC) technologies. These involve pumping cold water up from lower layers to condense warm waters that then run through a turbine. Salinity gradient which they derive energy via osmosis, the natural flow created between seawater and fresh water being passed through a turbine.

Advantages of the turbine:

- The turbine can be mounted on any type 
of foundation, including monopiles, gravity-based foundations, floating structures, or bridge attachements.The rotor diameter can be adjusted to ensure optimal energy extraction, according to site-specific conditions and water depth.

- Robustness through minimization of failure-prone and maintenance-intensive parts: - Direct drive, gearbox-free coupling

- Permanent magnet excitation Variable speed to accommodate

- fixed-pitch blades - Symmetric blade profile for

- bidirectional operation avoiding pitchand yaw requirements • Elimination of grease throughseawater ubrication technology $\bullet$ Elimination of dynamic seals.[8]

\section{LITERATURE REVIEW}

2.1 Different approaches used to improve the efficiency of the system

One of the compartment in the wind turbine system is related to transmitting the power from the blades to the generator to produce electricity. Turbine blades are usually rotating at low speed which is not suitable for electrical power generation. gearbox is able to overcome this deficiency by using a series of gear trains which multiply the input power. Even though these gearboxes have good efficiency, however a small change in their performance can affect the entire power generation specially in large scales. It is very important to be able to predict the power loss accurately in order to develop and design more efficient and reliable systems. The power loss within the gearboxes involves bearing, gears, seal and auxiliary losses [9]. Gear and bearing losses can be divided into two categories; no-load and load losses. No-load losses are those associating with rotation of mechanical components, even without torque transmission and the factors which affect them are mainly lubricants viscosity and density, internal casting design, operating conditions and immersion depth of component on a sump lubricated gearbox. Load dependent losses occur at the contact areas of power transmitting components which is related to coefficient of friction, sliding velocity and transmitted torque. On the other hand same concept applies to bearings, No -load losses depend on size, type, arrangement and immersion depth and lubricant viscosity. Load dependent bearings losses also depend on size, lubricant type, rolling and sliding conditions [10].

An experiment conducted by Pedro M.T. Marques [11] evaluate the effect of gear oils on the performance of the power loss amount. In their experiment four different gear oils was selected; a mineral (MINR), a polyalkylene Glycol (PAGD), a poly- $\alpha$-olefin (PAOR) and a mineral mixed with around $40 \%$ of PAMA (MINE). The basic physical properties of these oils are represented in table 2.1.

Table 2.1 the physical properties of the selected gear oils

\begin{tabular}{llllll}
\hline Parameter & Unit & MINR & PAOR & MINE & PACD \\
\hline Base oil & - & Mineral & $\begin{array}{l}\text { Poly- } \\
\text { a-olefin }\end{array}$ & Mineral+PAMA & Polyalkylene \\
& & & & Clycol \\
Density at $15^{\circ} \mathrm{C}$ & $\mathrm{g} / \mathrm{cm}^{3}$ & 0.902 & 0.859 & 0.893 & 1.059 \\
Thermal expansion coefficient $\left(a_{1} \times 10^{-4}\right)$ & - & -5.8 & -5.6 & -6.7 & -7.1 \\
Viscosity at $40^{\circ} \mathrm{C}$ & $\mathrm{cSt}$ & 319.25 & 324.38 & 328.59 & 290.26 \\
Viscosity at $70^{\circ} \mathrm{C}$ & $\mathrm{cSt}$ & 65.87 & 87.92 & 92.72 & 102.33 \\
Viscosity at $100^{\circ} \mathrm{C}$ & $\mathrm{cSt}$ & 22.41 & 35.27 & 37.88 & 51.06 \\
VI & - & 85 & 155 & 166 & 241 \\
\hline
\end{tabular}


The testes were performed based on the sequence which is displayed in table 2.2. after each experiment performed a few steps done to prepare the gearbox for testing with another gear oil. First the gearbox was removed from the gearbox test rig, the oil was drained and to make sure there is no particle or lubricant left, the gearbox was filled with solvent. Finally the gear box was filled with the new gear oil and then mounted back on the gearbox test rig to be ready for the next test.

Table 2.2 The sequence for the experimental test procedure

\begin{tabular}{lllll}
\hline $\begin{array}{l}\text { Test } \\
\text { sequence } \\
(/)\end{array}$ & $\begin{array}{l}\text { Input } \\
\text { speed } \\
(\mathrm{rpm})\end{array}$ & $\begin{array}{l}\text { Input } \\
\text { torque } \\
(\mathrm{N} \mathrm{m})\end{array}$ & $\begin{array}{l}\text { Input } \\
\text { power } \\
(\mathrm{kW})\end{array}$ & $\begin{array}{l}\text { Total } \\
\text { test time } \\
(\mathrm{h})\end{array}$ \\
\hline 1 & & 500 & 5.236 & 8 \\
2 & 100 & 750 & 7.854 & 8 \\
3 & & 1000 & 10.472 & 8 \\
4 & & 500 & 10.472 & 8 \\
5 & 200 & 750 & 15.708 & 8 \\
6 & & 1000 & 20.944 & 8 \\
7 & & 500 & 20.944 & 8 \\
8 & $400^{1}$ & 750 & 31.416 & 8 \\
9 & & $1000^{2}$ & 41.888 & 8 \\
\hline
\end{tabular}

The experimental results shows that among the tested gear oils the Ployalkylene Glycol (PAGD) had almost 30\% less power loss that MINR. And MINR which is a mineral oil additivated with a viscosity improving additive has the same effect as PAOR. It is obvious that changing the lubricant formulation not only can affect the power generated loss but also can have an impact on lifespan of the lubricated components.
A mathematical model was developed to study the behavior of wind turbines and the effect of different parameters such as, turbine swept area, wind speed, air density, and power coefficient as a function of pitch angle and blade tip speed[12]. The mathematical model was established in MATLAB/Simulink and was tested on V52 turbine which is being used and erected in most countries than any other turbines in VESTAS portfolio. The specification of this turbine is shown in table 2.3 .

Table 2.3 the specification of V52 turbine

\begin{tabular}{|c|c|}
\hline Rotor diameter & $52 \mathrm{~m}$ \\
\hline Area swept & $2,124 \mathrm{~m}^{2}$ \\
\hline Number of blades & 3 \\
\hline Power regulation & Pitch/OptiSpeed \\
\hline Air brake & Full blade pitch \\
\hline Cut-in wind speed & $4 \mathrm{~m} / \mathrm{s}$ \\
\hline Nominal wind speed & $16 \mathrm{~m} / \mathrm{s}$ \\
\hline Cut-out wind speed & $25 \mathrm{~m} / \mathrm{s}$ \\
\hline Nominal output & $850 \mathrm{~kW}$ \\
\hline
\end{tabular}

according to the Equation (1) which is used for measuring he mechanical power in the moving air, watt. By varying the three parameters; A, $\rho$, and $\mathrm{V}$ which are respectly the area swept by the rotor baldes $(\mathrm{m})$, density of the air $(\mathrm{kg} / \mathrm{m})$ and velocity of the air $(\mathrm{m} / \mathrm{s})$. the effect of them was evaluted and the result was illustrated in MATLAB. They have shown that the output power is directly related to the speed of the air as well as the to the swept area of the blades. It is known that the air density is proportional with pressure and inversely proportional with temperature of the air. Both temperature and pressure decreases as the 
elevation increases. As a result Changes in elevation will effect on the generated power.

The geographical dispersion is another factor that might effect on wind turbine performance. A research which was done in UK shows the performance is strongly affected by the frequency of weather pattern [13]. The experiment was conducted on four-dispersed sites in England: lynemouth, Dungeness, Fleetwood and St Mawgan. The station characteristics of these places are shown in table 2.4 .

Table 2.4 station characteristics of the located sites

\begin{tabular}{lcccc}
\hline & Latitude & Longitude & $\begin{array}{c}\text { Height above } \\
\text { sea level }(\mathrm{m}) \\
\text { of anemometer cups }\end{array}$ & $\begin{array}{c}\text { Height above } \\
\text { ground }(\mathrm{m})\end{array}$ \\
\hline Dungeness & $50.55 \mathrm{~N}$ & $00.58 \mathrm{E}$ & 16 & 10 \\
Fleetwood & $53.56 \mathrm{~N}$ & $03.01 \mathrm{~W}$ & 34 & 15 \\
Lynemouth & $55.12 \mathrm{~N}$ & $01.32 \mathrm{~W}$ & 32 & 10 \\
St Mawgan & $50.26 \mathrm{~N}$ & $05.00 \mathrm{~W}$ & 120 & 13 \\
\hline
\end{tabular}

It was found that the most dispiriting site was Fleet wood, on the other hand the potential output power generated from St Mawgan and Dungeness was influenced by the westerly flow over the UK. It was obtained that peak demand is associated with windy and cold weather rather than cold and calm conditions.

Various methods exists form improving the wind turbine s power output, a research that was conducted in Egypt evaluated the effect of three different approaches in order to increase the efficiency of the wind turbine system [14]. The performance was analyzed while changing the value of the pitch angle at three different angles;- $1.8^{\circ}$ (manufacturing setting tip angle), $-2.8^{\circ}$ and $0.8^{\circ}$. the second and third method was to place a vortex generators over the surface of the blade and at the tip blade to investigate the performance at low wind speed conditions. A nordtank $300 \mathrm{~kW}$ stall regulated with a horizontal axis was selected for the experiment. After the comparison of the data collected form the experiment it was found that the decrease of the pitch angle below the manufacturing design setting $\left(-1.8^{\circ}\right)$ can be useful specially in low wind speed sites, this significant effect on rotor efficiency can be seen from the curve in figure 2.1.

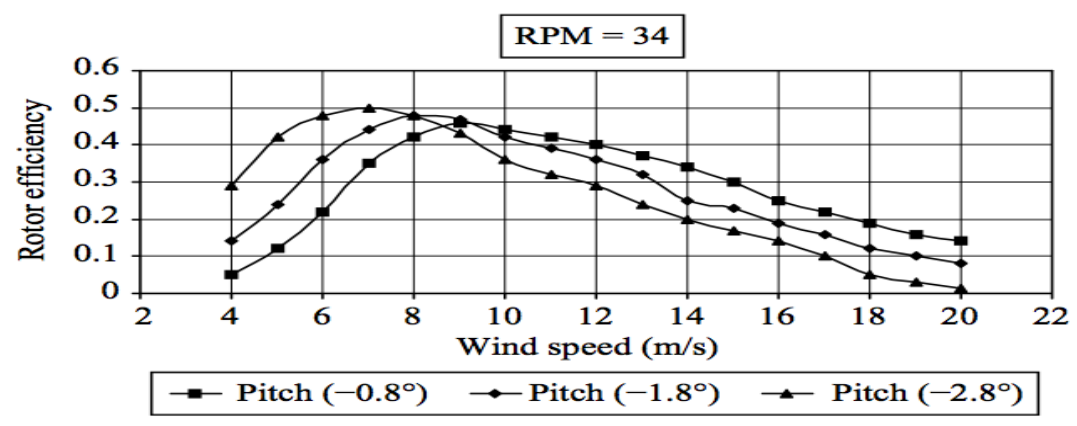

Figure 2.1 The effect of pitch angle on rotor efficiency $\left(C_{P}\right)$ of the wind turbine

By installing a rectangular vortex generator on blade as well as the tip parts, there was an improvement up to $35 \%$ at wind speed rate of 11 $\mathrm{m} / \mathrm{s}$ but this value drops very fast as the wind speed tends to go higher than $13 \mathrm{~m} / \mathrm{s}$, this comparison is shown in figure 2.2. 


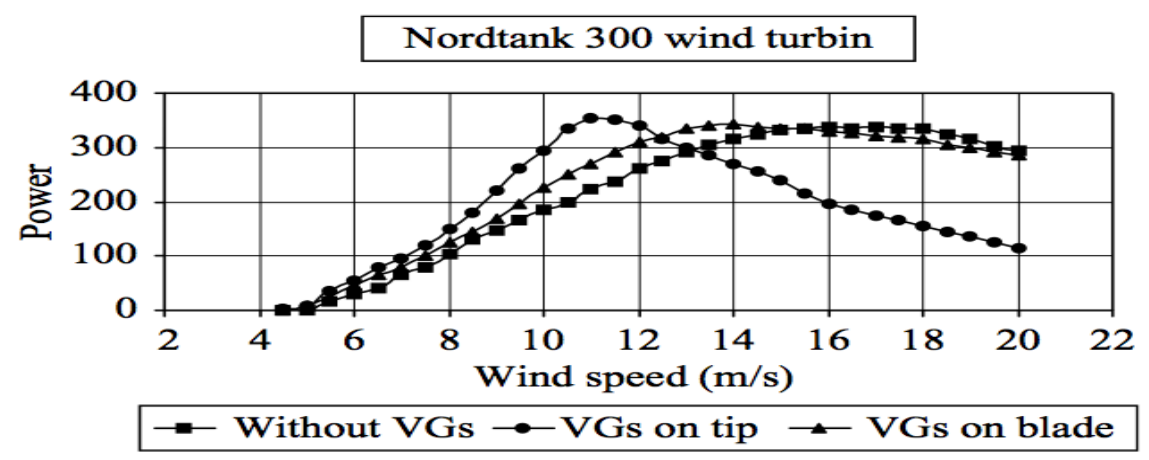

Figure 2.2 The effect of the rectangular VG on output power of the wind turbine

At the end it was concluded that the effect of kind, due to the increasing vortex floe over the rectangular VGs are better than the triangular blade surface (Figure 2.3).

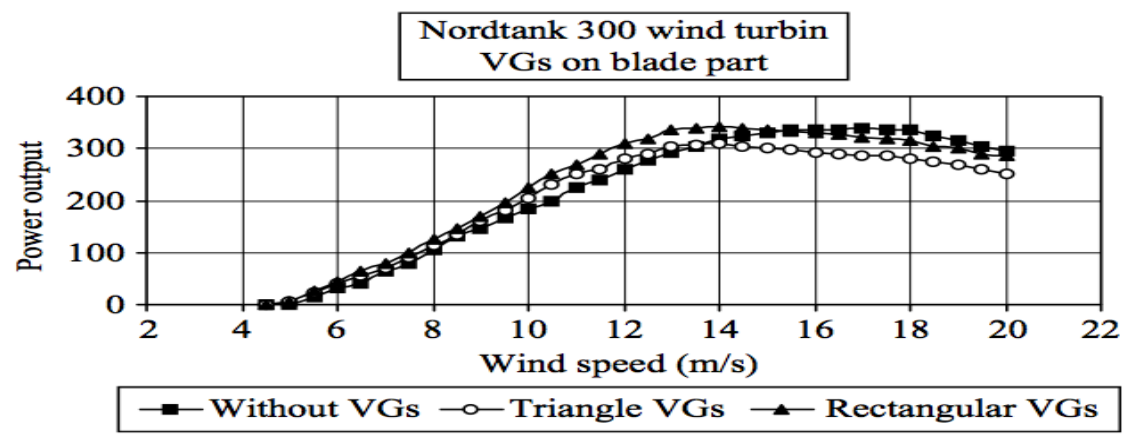

Figure 2.3 Effect of the two different kind of VG on the power output (kW)

In the study that was conducted in Iran [15] , the effect of air density on the performance of the wind turbine was investigated. A wind turbine that was designed to operate at sea level was used at four different locations in the country from east to west. For this purpose the blade was redesigned for each altitude, the tip speed ratio was added as another variable and the optimization procedure was repeated, while the other parameters remained unchanged. A genetic algorithm was established as well for the optimization which combined power extraction with starting time and included typical values of generator resistive torque. The performance of the blade designed for operating at sea level reduced at higher altitudes. The decline in the power coefficient was due to the reduction in air density but the much larger degradation in starting was due to the increasing significance of the resistive torque which was assumed to be independent of altitude. Two approaches was performed to improve the performance of blades at those altitudes. First approach was to optimize the geometry of the blades in terms of twist and chord for the appropriate air density. Second was achieved by adding a tip speed ratio to the other variables in the optimization process.

In another research done in Egypt was found the effect of some parameters design parameters on the performance of a Giromill vertical axis wind turbine (Figure 2.4), such as pitch angle, turbine radius and chord length [16]. 


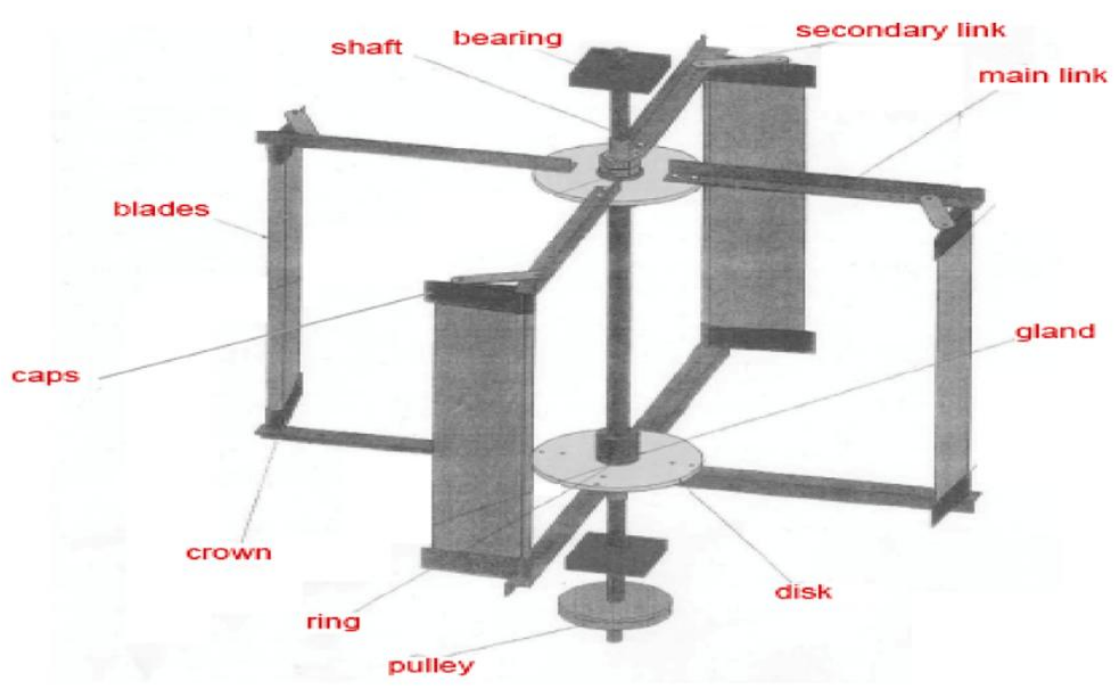

Figure 2.4 Schematic diagram for Giromill vertical axis wind turbine

The investigation was done by varying these variables plus the number of blades and airfoil type, then the results was used for the compare with the previously published works (table 2.5).

Table 2.5 the comparison between the present and previous experiment results

\begin{tabular}{llll}
\hline Parameters & $\begin{array}{l}\text { Present exp. Previous exp. Previous } \\
(8 \mathrm{~m} / \mathrm{s})\end{array}$ & $\begin{array}{l}\text { Prious } \\
(13 \mathrm{~m} / \mathrm{s})[8]\end{array}$ & $\begin{array}{l}\text { exp. }(4 \mathrm{~m} / \mathrm{s}) \\
{[8]}\end{array}$ \\
\hline Number of blades & 4 & 4 & 4 \\
Airfoil type & NACA & 0024 NACA 0018 & NACA 0018 \\
Radius of rotor $(\mathrm{m})$ & 0.4 & 1.6 & 1.6 \\
Span length of blades $(\mathrm{m})$ & 0.7 & 2 & 2 \\
Chord length of blades $(\mathrm{m})$ & 0.15 & 0.45 & 0.45 \\
Pitch angle $\left({ }^{\circ}\right)$ & 10 & 8 & 8 \\
Wind speed $(\mathrm{m} / \mathrm{s})$ & 8 & 13 & 4 \\
\hline
\end{tabular}

from the experimental result the following were concluded:

- The pith angle has an significant effect on $\mathrm{C}_{\mathrm{P}}, \mathrm{C}_{\mathrm{t}}$ and $\lambda$ (minimum value was generated at $10^{\circ}$ )

- The chord length is an important parameter on the $\mathrm{C}_{\mathrm{P}}, \mathrm{C}_{t}$ and $\lambda$ (by increasing the chord length these values are increased)

- The turbine radius has as considerable effect on the $\mathrm{C}_{\mathrm{P}}, \mathrm{C}_{t}$ and $\lambda$ (increasing turbine radius increased these values as well)

- From increasing the number of blades from two to four there was an noticeable increase in the $\mathrm{C}_{\mathrm{P}}, \mathrm{C}_{\mathrm{t}}$ and $\lambda$.
Of course one of the technical and theoretical interesting topics of large-scale offshore wind turbines are Aerodynamic analysis and computation of the wind turbine rotor. It has been proved that the essential criterion of a high performance wind turbine is a highest possible annual usable energy pattern facto and a smallest possible dimension, producing the maximum annual power and obtaining the maximum wind energy [17]. The influence of the mentioned on the performance of a wind turbine operated in china's offshore was studied. The variation patterns of the aerodynamic parameters was captured, analyzed, and compared with each other. They found out that in order to accurately determine the annual usable energy pattern factor of the wind turbine, two important requirements should be fulfilled. 
First, the characteristics of annual wind speed frequency should be accurately determined by means of actually surveying the atmospheric condition at the wind sites. Second, the blade pitch should be regulated in a low wind condition to ensure the possibility of the higher power efficiency of the wind turbine.

The deep currents at depths of 700 to 800 have been recorded from 1999 to 2010 in the japan east sea [18].The observational findings in this research are as follow:

I. The mean circulation is strongest in the eastern japan basin, while overall currents in the Ulleung Basin are weaker that that in the eastern japan basin and western japan yamato basin

II. It was found that The eddy kinetic maximum energy is maximum in the western japan basin.

III. Cyclonic bottom following
characteristics prevail in the bin-
averaged velocities

China pays much attention to the renewable energy, They believe that ocean energy is a Necessary addition to existance renewable energy to meet the energy demand of the areas and islands where traditional forms of energy are not applicable anymore. A overview study which was done on ocean renewable energy in china [19]shows the status of ocean energy develpoment from five differents technologies; Tidal energy, Marine Current, Wave enrgy, Ocean Thermal energy and salinity gradient energy.

In a study for A Special Mechanism for Energy Harvesting from Ocean Currents,Tides, and Waves in university of connecticut [20], they showed a detailed proof-of-concept study of the hydropower model, including the underlining theoretical principles. Laboratory test results demonstrating the displacement output obtained from water flow using a small scale reciprocating system. The conclusions from the theoretical, experimental and analytical analysis of the hydropower system are as follows:

A. The lift force on the cylinder increases with the increase in size of cylinder, rotational velocity and flow velocity of water.

B. Similarly, the rate of cylinder- piston displacement also increases with the increase in in size of cylinder, rotational velocity and flow velocity of water.

C. The result from finite element analysis for the prediction of forces and displacement of the system was very close to the result from the laboratory experiments.

D. The output voltage and power increases with the increase in the displacement rate or velocity of the system.

A mathematical and simulation model that was done in florida atlantic [21] represents the CPlane (The "C-Plane" is a submerged variable depth ocean current turbine that is tethered to the sea floor and uses sustained ocean currents to produce electricity) as a rigid body with moveable control surfaces that is moored with three linear elastic cable elements. Gravitational, buoyancy, hydrodynamic, cable, gyroscopic, and inertial forces are included and a PC-based dynamics simulation is created.(Figure 2.5). The gravitational, buoyancy, hydrodynamic, control, propulsive, cable, and gyroscopic forces are calculated as a function of the states of the system, the water velocity, and the control surface deflections. And the results shows The CPlane is stable when operating in active mode and is able to reach heights throughout the desired operating range with zero pitch, roll, and yaw. When operating in null mode, the C-Plane stability is reduced but the C-Plane can still reach the desired depths and can surface for maintenance. 


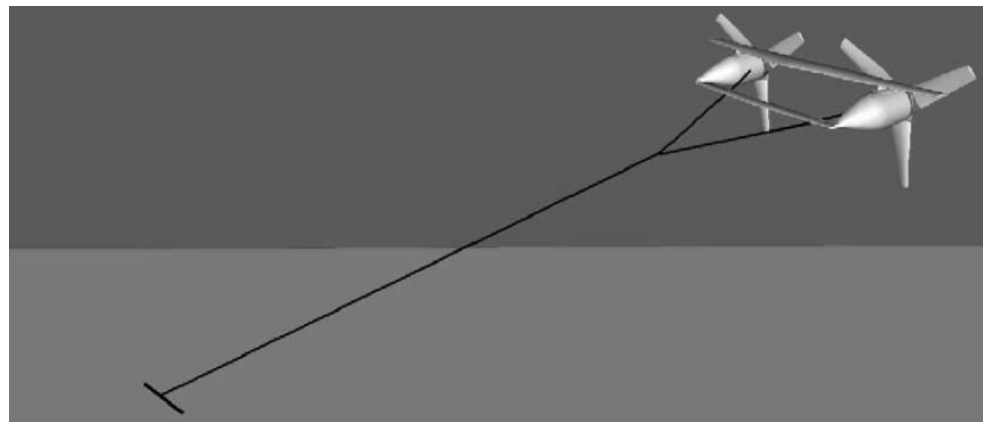

Figure 2.5 Illustration of a C-Plane under normal operating conditions

In a research done in the university of british columbia [22]a Numerical analysis of the characteristics of vertical axis tidal current turbines. This syrudy identifies four different characteristics(power output, torque fluctuation, induced velocity, and acoustic emission) of the turbine, which can be used to develop standards for tidal current turbines. In the near future, the critical values of these characteristics should be determined. More experimental tests are required to identify these critical values.In addition troduce the power fluctuation coefficient, the torque fluctuation coefficient, the induced velocity angle, and the noise intensity of tidal current turbines. For a turbine, a high power coefficient is desired along with a low power fluctuation coefficient. From a costefficiency point of view, one wants to find an optimal design TSR that balances the high power coefficient against a low fluctuation coefficient, possibly with the assistance of a precise angular velocity controller. Furthermore, the torque fluctuation coefficient should also be high enough to reduce the burden on the electric power generator and increase the reliability of the turbine. During the UBC towing experiment, we found that using auxiliary structures can signifi- cantly reduce the torque fluctuation, and that the auxiliary struc- ture can be designed by studying the induced velocity.

\section{CONCLUSION}

For the first time it can be seen renewable energy generating options-wind power-in a position to compete with the generation technologies of the last century. A variety of players are engaged in pushing forward wind projects worldwide. Many manufacturers have developed joint ventures in various countries around the world. This globalization trend is likely to continue as financial institutions are beginning to view the wind industry as a promising investment opportunity. As more countries are added to the wind energy

Yet, as land constraints, lower average wind speeds in future projects, as well as possibly lower energy prices impact the economics of future projects wind penetration will likely begin to saturate and the growth rates quoted above slow. This trend may be offset by increasing the capacity of turbine installed and allowing operators to lower generation costs.

\section{References}

RENEWABLE ENERGY SOURCES, Antonia V. Herzog Timothy E. Lipman Daniel $M$. Kammen

Types of wind turbines, Teacher Geek 2006

International School on Energy, "New Strategies for Energy Generation, Conversion and Storage" Villa Monastero, Varenna (Lake Como) 30th July - 4th August 2012

Wind turbines, mechanical Engineering , University of Boston

Mechanical Engineering for Renewable Energy Systems Dr. Digby Symons Wind Turbine Blade Design,(2000)

Wind Turbine - Materials and Manufacturing Fact Sheet, Dan Ancona and Jim McVeigh, August 29, 2001

Wind Energy Math Calculations, Measuring the Swept Area of Your Wind Turbine,(2008) 
OPTIMIZATION OF GEARBOX EFFICIENCY, B.-.R Höhn, K. Michaelis, M. Hinterstoiße (2009)

Catalogue 6000/! EN · June 2008

Efficiency of a gearbox lubricated with wind turbine gear oils Pedro M.T. Marques(2014)

Evaluation of parameters affecting wind turbine power generation Omar Badran

Effects of Geographical Dispersion on wind turbine performance in England: A Simulation, J. P. Palutikof (1989)

Suggestions for improving wind turbines power curves Mohammed G. Khalfallah(2007)

Effect of air density on the performance of a small wind turbine blade: A case study in Iran, Abolfazl Pourrajabian,(2014)

Effect of some design parameters on the performance of a Giromill vertical axis wind turbine, M. El-Samanoudy(2010)

Deep currents obtained from Argo float trajectories in the Japan/East Sea Jong Jin Park, South korea

An overview of ocean renewable energy in China,Shujie Wang

A Special Mechanism for Energy Harvesting from Ocean Currents,Tides, and Waves,By Ramesh B. Malla,University of connecticut

Design of a prototype ocean current turbinePart I: mathematical modeling and dynamics simulation,J. VanZwieten, florida atlantic university (2005)

Numerical analysis of the characteristics of vertical axis tidal current turbines, $\mathrm{Ye} \mathrm{Li}$, university of columbia (2005) 